\title{
Assessing the reproducibility of discriminant function analyses
}

Rose L Andrew, Arianne YK Albert, Sebastien Renaut, Diana J Rennison, Dan G Bock, Tim Vines

Data are the foundation of empirical research, yet all too often the datasets underlying published papers are unavailable, incorrect, or poorly curated. This is a serious issue, because future researchers are then unable to validate published results or reuse data to explore new ideas and hypotheses. While data files may be securely stored and accessible, they must also be accompanied by accurate labels and identifiers. To assess how often problems with metadata or data curation affect the reproducibility of published results, we attempted to reproduce Discriminant Function Analyses (DFAs) from the field of organismal biology. DFA is a commonly used statistical analysis that has changed little since its inception almost eight decades ago, and therefore provides an excellent case study to test reproducibility. Out of 100 papers we initially surveyed, fourteen were excluded because they did not present the common types of quantitative result from their DFA or gave insufficient details of their DFA. Of the remaining 86 datasets, there were 15 cases for which we were unable to confidently relate the dataset we received to the one used in the published analysis. The reasons ranged from incomprehensible or absent variable labels, the DFA being performed on an unspecified subset of the data, or the dataset we received being incomplete. We focused on reproducing three common summary statistics from DFAs: the percent variance explained, the percentage correctly assigned and the largest discriminant function coefficient. The reproducibility of the first two was fairly high ( 20 of 26 , and 44 of 60 datasets, respectively), whereas our success rate with the discriminant function coefficients was lower (15 of 26 datasets). When considering all three summary statistics, we were able to completely reproduce 46 (65\%) of 71 datasets. While our results show that a majority of studies are reproducible, they highlight the fact that many studies still are not the carefully curated research that the scientific community and public expects. 
1 Title: Assessing the reproducibility of discriminant function analyses

2 Authors: Rose L. Andrew 1,2,*, Arianne Y.K. Albert ${ }^{3}$, Sebastien Renaut ${ }^{1,4}$, Diana J. Rennison ${ }^{1}$, 3 Dan G. Bock ${ }^{1}$, Timothy H. Vines ${ }^{1,5}$,

4

5 Affiliations: ${ }^{1}$ Biodiversity Research Centre, University of British Columbia, 6270 University

6 Blvd Vancouver BC, Canada, V6T 1Z4.

$7 \quad{ }^{2}$ School of Environmental and Rural Science, University of New England, Armidale, NSW, 8 2351, Australia.

$9{ }^{3}$ Women's Health Research Institute, 4500 Oak Street, Vancouver, BC, Canada V6H 3N1.

$10{ }^{4}$ Institut de recherche en biologie végétale, Département de sciences biologiques, Université de 11 Montréal 4101 Sherbrooke est, Montréal, QC, Canada

$12{ }^{5}$ Molecular Ecology Editorial Office, 6270 University Blvd Vancouver BC, Canada, V6T 1 Z4.

14 *Author for correspondence: Tim Vines, vines@zoology.ubc.ca 


\section{Abstract}

19 Data are the foundation of empirical research, yet all too often the datasets underlying published

20 papers are unavailable, incorrect, or poorly curated. This is a serious issue, because future

21 researchers are then unable to validate published results or reuse data to explore new ideas and

22 hypotheses. While data files may be securely stored and accessible, they must also be

23 accompanied by accurate labels and identifiers. To assess how often problems with metadata or

24 data curation affect the reproducibility of published results, we attempted to reproduce

25 Discriminant Function Analyses (DFAs) from the field of organismal biology. DFA is a

26 commonly used statistical analysis that has changed little since its inception almost eight decades

27 ago, and therefore provides an excellent case study to test reproducibility. Out of 100 papers we

28 initially surveyed, fourteen were excluded because they did not present the common types of

29 quantitative result from their DFA or gave insufficient details of their DFA. Of the remaining 86

30 datasets, there were 15 cases for which we were unable to confidently relate the dataset we received to the one used in the published analysis. The reasons ranged from incomprehensible or

32 absent variable labels, the DFA being performed on an unspecified subset of the data, or the

33 dataset we received being incomplete. We focused on reproducing three common summary

34 statistics from DFAs: the percent variance explained, the percentage correctly assigned and the

35 largest discriminant function coefficient. The reproducibility of the first two was fairly high (20

36 of 26 , and 44 of 60 datasets, respectively), whereas our success rate with the discriminant

37 function coefficients was lower (15 of 26 datasets). When considering all three summary

38 statistics, we were able to completely reproduce $46(65 \%)$ of 71 datasets. While our results show

39 that a majority of studies are reproducible, they highlight the fact that many studies still are not

40 the carefully curated research that the scientific community and public expects. 


\section{Introduction}

43 Published literature is the foundation for future research, so it is important that the results 44 reported in scientific papers be supported by the underlying data. After all, we cannot easily predict which aspects of a paper will prove useful in the future (Wolkovich et al. 2012), and if a portion of the results are wrong or misleading then subsequent research effort may well be wasted (e.g. Begley \& Ellis 2012). One relatively simple way to judge the validity of published research is to obtain the original data analyzed in the paper and attempt to repeat some or all of the analyses: this allows researchers to retrace the path the authors took between the raw data and their results. The idea of reproducibility in research is becoming a topic of great interest and this movement is gaining traction with journals (Announcement: Reducing our irreproducibility 2013; McNutt 2014). There is clearly a need to quantify the validity of published research, yet there have been only a modest number of published studies that have tried to reproduce the results of published papers (e.g. Ioannidis et al. 2009; Gilbert et al. 2012; Errington et al. 2014), most likely because it is often difficult to access the underlying data (Wicherts et al. 2006; Savage \& Vickers 2009; Drew et al. 2013; Vines et al. 2013).

Even when the data file is available, one common problem that hampers reanalysis is poor data curation: it is sometimes difficult to relate the dataset provided by the authors upon request or archived at publication to the one described in the paper (Michener et al. 1997; Ioannidis et al. 2009; Gilbert et al. 2012). For example, variable names may differ between the obtained dataset and the one described in the study, or there may be differences in the number of variables or data points (see White et al. 2013). It is typically not possible to reproduce the authors' analyses in these cases, and moreover the data may not be considered sufficiently reliable for testing new hypotheses.

The current study had two goals: to assess a) how often poor data curation prevented re-analysis, and b) how often we could reproduce authors' results when the obtained dataset did match the one described in the paper. We made use of 100 datasets acquired from authors as part of an earlier study assessing the effect of time since publication on data availability (Vines et al. 2014). The articles we chose had to i) contain morphometric data from plants or animals, ii) have analysed the morphometric data with a Discriminant Function Analysis (DFA), and iii) have not previously made the data available online. To make the data set manageable in size, we selected 
72 only those studies published in odd years (between 1991 and 2011) as detailed in Vines et al. 73 (2014).

74 We focused on morphometric data because it has been collected in a similar fashion for decades 75 (e.g. with Vernier callipers or a binocular microscope), so datasets from a range of time periods 76 are expected to be similar in size and format. We used similar logic when selecting the analysis 77 to reproduce: Discriminant Function Analysis (Fisher 1936) has been applied to morphometric 78 datasets for many decades. The function gives the best linear combination of morphometric variables that distinguishes between two or more known groups (e.g. sexes, populations, species). Typically, a sample of individuals with known affiliations is used to find the minimum

81 set of variables that distinguishes the groups, and a discriminant function composed of the 82 chosen variables is then used to classify unknown individuals. While computer processing power 83 has greatly increased over the years, the way the analysis has been performed has remained the 84 same. We can therefore reasonably compare DFAs from papers with a wide range of publication dates, allowing us to investigate how changing analysis software or date of publication affect reproducibility. In combination with Vines et al. (2014), our results quantify the extent of the challenges facing science publication, both in terms of acquiring the original data analysed in the paper, and in terms of the proportion of analyses that are poorly curated or cannot be reproduced.

\section{Materials and methods}

As part of the Vines et al. (2014) study, we received 100 datasets from authors. For papers reporting a classical DFA of morphometric data, linear or quadratic DFA were considered, as were stepwise analyses where a) the variables in the final model were presented and b) at least one of three common metrics (see below) was presented. This allowed us to attempt to reproduce

94 the final model as a simple linear DFA. Studies employing stepwise analysis of relative warps or 95 Fourier-transformed data were also excluded at this point, as these studies unfortunately did not 96 indicate which variables were included in the final model. A study entirely written in a foreign 97 language (Spanish) was also excluded.

98 For each remaining study, we followed the protocol below. 
1) We first assessed the description of the methodology, checking whether the paper adequately described the groupings and morphometric variables used in the analysis.

2) We examined the data files (in some cases multiple files were supplied), which sometimes required specialised file formats to be converted to text. This was carried out using the R packages 'foreign' (R Core Team 2013) and 'RODBC' (Ripley \& Lapsley 2013). If the data file was clearly wrong (e.g. a summary table, instead of raw data) we categorized the paper as 'Incorrect data file'.

3) We assessed whether the metadata contained in the data file, in other files supplied by the author or in the accompanying email were complete and could be related to their description in the paper. We classified papers missing sample names and those with unclear population groupings as having 'Insufficient metadata'. This category also included papers for which variable labels were in a foreign language and, even when translated in English (using http://ranslate.google.ca), could not be matched to the variables reported in the paper. However, we accepted files with unlabeled data columns where the identity of each column could be verified using information in the paper or supplied by the authors; the latter information came either from the files provided or their email message.

4) We then went through the data deleting rows that contained missing data or other samples that the paper stated were not included in the analysis. Once this was completed, we identified discrepancies between the paper and the dataset in terms of sample sizes or number of variables, and categorized papers for which variables were missing or for which sample sizes did not match those reported in the paper as 'Data discrepancy'. back-projection) using the $R$ packages 'multigroup' (Eslami et al. 2014) and 'cpcbp' (Bolker \& Phillips 2012).

6) When there was more than one DFA analysis that met our criteria in a paper, we selected only the first one. We recorded whether raw or standardised coefficients were 
presented, whether cross-validation was used in the classification of individuals, and the statistical software used. The year of publication was recorded for each paper.

129 Based on a preliminary survey of the papers, we identified three DFA metrics to reproduce: the percentage of variance explained (PVE), the percentage of samples assigned correctly (PAC),

131 and the largest model coefficient. These three summary statistics are commonly reported for

132 DFAs, and are useful for interpreting DFA in a meaningful manner (Reyment et al. 1984),

133 although the detail in which DFAs are described varies greatly depending on the focus of the

134 paper. PVE and PAC are complementary indicators of the discriminatory power of a

135 discriminant function, whereas the function coefficients make up the formula for assigning

136 unknown samples to one group or another.

137 Our reanalysis procedure was designed to produce a single value for each metric per paper.

138 Where possible, we compared the PVE for the first axis, which explains the greatest amount of

139 variance in the model. When PVE was reported as the sum of the first two or three axes, we 140 compared the summed PVE. We calculated the overall PAC, or the PAC for a particular group if

141 the overall percent assigned correctly was not reported in the paper. For the coefficient, we

142 selected the variable with the largest absolute coefficient, and determined from the paper whether

143 the raw or standardised coefficient was used.

144 Although the original analyses used diverse statistical packages, we performed all discriminant 145 function reanalyses in the statistical software R v3.2.0 (R Core Development Team 2011), using 146 the functions 'lda' (in the MASS package; Venables \& Ripley 2002) with default parameters.

147 Within R, we estimated each summary statistic using proportional or flat priors and used the 148 value that was closest to the published value. Authors reported a variety of methods for 149 assignment when calculating PAC, ranging from standard classification functions based on all 150 data, to omitting one quarter of the data as a validation set. In our reanalysis, classification was 151 carried out using leave-one-out (jackknife) cross-validation or direct prediction in 'lda', based on

152 the description of the analysis in the paper. When authors did not specify whether cross-

153 validation or direct prediction was used, we performed both and selected the value that was 154 closest to the published result. While this approach biases the results towards the published 155 value, it avoids unfair treatment of studies that used default parameters for their chosen software. 
156 Our R code is provided in the Supplementary Materials, along with example datasets from 157 Gugerli et al. (1997), Berzins et al. (2009), and Dechaume-Moncharmont et al. (2011). IAs we

158 do not have explicit permission from the original authors, we are unable to share the remaining 15997 datasets (see Vines et al. 2014). We considered the analysis to have been reproduced if the 160 PVE, coefficient, or PAC was within 1\% of the published value (termed 'matched'), or was 161 'close' if it was within 5\% of the published value.

162 We used generalised linear models (the core ' $\mathrm{glm}$ ' function in R) to assess whether publication 163 year affected the likelihood of problems in the data sets that would prevent attempts to reproduce 164 the DFA results. Given a binomial model, we tested the effect of publication year on categorizing a study as 'Insufficient metadata' or 'Data discrepancy' (see points 3-4 above for categories description). A Fisher's exact test was used to test the effect of statistical software on data problems and on the success of the reanalysis, combining software used in just one study (SPlus, STATGRAPHICS, and LINDA (Cavalcanti 1999)) into a single category (“other").

Although we contacted authors again to ask for their preferences regarding acknowledgment or anonymity, we did not seek further information (e.g. metadata or analysis parameters) to inform our reanalysis. We also note that we are unfortunately unable to provide all 100 of the datasets reanalysed here, in an attempt to make this study reproducible: the email sent by Vines et al (2014) requesting these datasets stated "Our analysis will not identify individual studies, but will instead focus on overall patterns and trends. Your responses will therefore be completely confidential." Obtaining additional permission to make all datasets public alongside this paper would be very challenging, as evidenced by the $66 \%$ response rate to our email merely asking authors how they would prefer their work to be cited.

\section{Results}

180 The current study used 100 data sets originally gathered by Vines et al. (2014). Fourteen of those data sets were excluded from our reanalysis attempt (Tables $1 \& 2$ ): one paper was entirely in a

182 language other than English (Spanish); two did not perform classical DFA; two used non-

183 morphological data in their DFA; six did not present any of the metrics that we were attempting 
184 to reproduce; and three were based on stepwise analysis for which the final set of Fourier185 transformed variables or relative warps were not specified.

186 Of the 86 remaining studies, the data files provided for two (2.3\%) were classified as 'Incorrect 187 data file': summary tables were provided instead of morphometric data, or the data set provided 188 was used for a different analysis from the same paper (Figure 1, Table 1). Six others (7.0\%) were 189 categorized as 'Insufficient metadata', as columns in the data files could not be matched to the 190 variables described in the paper. Assignment as 'inadequate metadata' was due to a combination 191 of incomprehensible abbreviations in column headings (studies \#36 and \#80), missing column 192 labels (\#44), unclear row groupings (\#13 and \#43) and the use of a language other than English 193 (study \#29 in Table 2). Seven were classified as 'Data discrepancy': five data sets (5.8\%) did not 194 match the expected sample sizes, and two (2.3\%) were missing variables.

195 We found no effect of publication year on the probability of having insufficient metadata (odds 196 ratio 0.98 [95\% CI 0.84-1.15], $P=0.82$ ) and no effect of year on the probability of incorrect or 197 inconsistent data ('Data discrepancy' or 'Incorrect data': odds ratio 1.06 [95\% CI 0.90-1.26], $P$

$198=0.45)$. Combining these main types of data problems that prevented us from attempting 199 reanalysis ('Incorrect data file', 'Insufficient metadata', 'Data discrepancy'), there was no effect 200 of year (odds ratio 1.06 [95\% CI 0.95-1.20], $P=0.28$ ).

201 Where stated, the type of software (SAS ${ }^{\circledR}$ (SAS Institute, Cary, NC, USA), SYSTAT (SYSTAT

202 Software Inc., Richmond, CA, USA), SPSS (SPSS Inc., Chicago, IL, USA), MATLAB

203 (Mathworks, Natick, MA, USA), STATISTICA (Statsoft, Tulsa, OK, USA), JMP (SAS Institute, 204 Cary, NC, USA), R (R Core Development Team 2011), S-Plus ${ }^{\circledR}$ (TIBCO Software Inc., Palo 205 Alto, CA, USA), STATGRAPHICS (StatPoint Inc., Rockville, MD, USA) and LINDA 206 (Cavalcanti 1999)) used for the initial study had a significant effect on the probability of data 207 problems (Fisher's exact test, $P=0.012$ ). This was largely due to a high likelihood of data 208 problems (26.7\%) among data sets originally analysed with SAS, compared with the overall 209 proportion (17.4\%; see Table 1).

210

211 We attempted a reanalysis of the DFA for the remaining 71 studies, and the results are

212 summarised in Table 2. Our results regarding the PVE were generally close to the published

213 values (Pearson correlation coefficient, $r=0.94, P<0.0001$; Figure 2). Of the 26 reanalysed data 
214 sets reporting this statistic, our reproduced value was within $1 \%$ of the published value in 20

215 cases (80\%), and within 5\% of the published value in 24 cases $(92 \%)$. The PAC statistic was also

216 often reproduced (Pearson's $r=0.95, P<0.0001$; Figure 3). Of 60 reanalyses of PAC attempted,

217 our values differed from the published value by $1 \%$ or less in $44(73 \%)$ cases, while $55(93 \%)$

218 were within 5\%. Discriminant function coefficients were reproduced less frequently in the

219 reanalysis. Using the absolute value of the coefficient to exclude sign differences, reproduced

220 values were within $5 \%$ of the published value for $15(58 \%)$ of the 26 data sets reanalysed for this

221 statistic, and each of these values was also within 1\%. There was still a strong correlation

222 between the published value and our estimate (using absolute values, Pearson's $r=0.96, P<$

223 0.0001; Figure 4).

224 Of all 112 reanalysed PVE, PAC and coefficient values, 79 (71\%) were within $1 \%$ of the 225 published value, and $95(85 \%)$ were within 5\% (Table 2). Considering the reported summary

226 statistics together for each paper, our reanalysis failed to replicate any value in the paper at the 227 most stringent level (within 1\%) in 12 studies (17\% of the total 71 data sets; Table 1); however,

228 we were able to partially reproduce $13(18 \%)$ studies and completely reproduce the results in 46

229 studies (65\%). The reanalysed values were within 5\% of the published value for all three

230 statistics for 56 (79\%) of studies.

231 There was no effect of publication year on discrepancies between the published and our values

232 for PVE, coefficients or PAC (Fisher exact test, $P>0.2$ in each case). Sample sizes were

233 sufficient for a reliable test of the software effect for PAC only and this effect was not significant

234 (Fisher's exact test, $P=0.81$ ). There was also no effect of software on the overall reanalysis

235 success (Fisher's exact test, $P=0.81$ ).

\section{Discussion}

237 Confidence in scientific research is boosted when published results can be independently

238 reproduced by other scientists (Price 2011). Assuming that the raw data can be obtained (which

239 is typically difficult, e.g. Wicherts et al. 2006; Wicherts et al. 2011; Vines et al. 2013; Vines et

240 al. 2014), several obstacles still remain. First, poor data curation (e.g. unintelligible column

241 headings or missing samples) or inadequate methods description can mean that the dataset

242 obtained cannot be matched to the one described in the paper, preventing reanalysis at the outset. 
243 Second, even when the datasets do match, some aspects of the results may be inherently harder 244 to reproduce than others, perhaps because there are multiple calculation methods for the same 245 summary statistic, or because the calculation involves 'random walk' estimation (e.g. Gilbert et 246 al. 2012). By following recommended data sharing practices (e.g. White et al. 2013), we can aim 247 towards reproducible research, and re-usable datasets.

248 In this paper we attempted to reproduce the results of Discriminant Function Analyses (DFA) for 249100 datasets of papers published between 1991 and 2011. In contrast to the striking decline in 250 data availability over time (Vines et al. 2014), we found no evidence that the reproducibility of 251 DFAs decreased with time since publication. There was also no relationship between publication 252 year and the proportion of datasets with data problems that prevented reanalysis, or with the 253 proportion of reproducible results.

254 We could not attempt reanalysis for 17\% (15 of 86 papers) of data sets because of obvious 255 problems in the data file. These problems included the wrong data file being provided, missing 256 data (individuals or variables), differences in the labels of variables between data files and 257 published work, or unspecified subsetting of the data files prior to the analytical steps. While 258 some of these problems could be solved through further communication with the authors, we 259 wanted our study to reflect the long-term reusability of the data, when contacting the authors 260 becomes increasingly difficult (Vines et al. 2014). Digital information is rapidly moving towards 261 a more centralised online system ("the cloud", Armbrust et al. (2010)). Similarly, the 262 responsibility for data preservation is being lifted from scientists to online repositories (e.g.: 263 Dryad (www.datadryad.org), figshare (www.figshare.com), NCBI (www.ncbi.nlm.nih.gov)).

264 Given this paradigm shift, we recommend more attention be given to metadata quality and to the 265 curation of the archived files (Michener et al. 1997). For instance, if data are size-adjusted or 266 manipulated in other ways, both pre- and post-transformation data should be archived. Perhaps

267 the most critical piece of information is the link between column labels in the data file and the 268 variables described in the paper. We were unable to determine the correct columns or rows for $2697 \%$ of datasets. While we were able to convert all data files to text format, the loss of metadata 270 may stem from this conversion (in one case, this had to be typed by hand, because data file 271 provided was from a scanned hardcopy of the data in a MSc thesis appendix). In line with 272 previous authors on this topic (Borer et al. 2009; Whitlock 2011), we recommend storing data in 
273 text-based data formats (such as comma- or tab-separated files), as these are non-proprietary and 274 accessible across the range of statistical software packages. Also in line with previous papers, we 275 recommend publishing the code used in analysis as it is often difficult to provide a full

276 description of the parameters used for a given analysis in the methods section of a journal article 277 (Wolkovich et al. 2012). This can be done as part of the supplementary material or in online 278 repositories such as GitHub (see Ram 2013) or Zenodo, which provides a DOI and archives the 279 permanent version of the code.

280 Among the 71 data sets that were suitable to be reanalysed, we were able to get within $1 \%$ of the 281 published value for at least one of the three statistics that we focused on (PVE, PAC and the 282 largest (absolute) coefficient) for 59 studies (83\%). There were strong positive correlations 283 between published and reanalysed values for statistics reported in DFA, which suggests that 284 replication, in the broad sense, is possible when the proper metadata are provided and with 285 adequate curation of the data file. Slight discrepancies could be due to differences in rounding, or 286 differences in how data are handled by the various software packages. Although data file 287 problems that preclude reanalysis appear to be associated with some software (particularly SAS, 288 see Table 1), there was no effect of software on the reproduction of the published results in our 289 reanalyses.

290 Evaluating whether the DFA metrics analysed here fall within 5\% of the published values is, in 291 our view, a reasonable test of reproducibility. However, it is uncertain how much the original 292 conclusions from these studies would change based on the values we have obtained. The 293 reproducibility of inference is an aspect of reproducibility that we admittedly did not explicitly 294 address in this study. Additionally, while DFA was not always a central or essential component 295 of the original study, its reproducibility is an important indicator of the underlying data's quality 296 and completeness. Such checks are a worthwhile consideration when archived data are being re297 used for new purposes.

298 The reproducibility of the DFA varied depending on the summary statistic examined, ranging 299 from $58 \%$ within $1 \%$ of the original value for the largest coefficient to $73 \%$ for the more 300 complex PAC analyses, and 77\% for PVE The discriminant function coefficients were less likely 301 to be reproduced, even when PVE and/or PAC matched. The procedures used to standardise 302 model coefficients and calculate PAC differed among statistical packages and studies. For 
303 instance, if we had used only jackknifing for all PAC reanalyses, only $56 \%$ of published values

304 would have been reproduced (results not shown). While this clearly does not invalidate the

305 original results, it does highlight another obstacle to successfully reproducing the authors'

306 results: some summary statistics may be inherently harder to reproduce, particularly when there

307 are numerous calculation methods, as is the case here, or when the estimation procedure makes

308 use of stochastic numerical optimisation methods (e.g. Gilbert et al. 2012).

309 In comparison with our previous study of reproducibility of analysis using the genetic analysis

310 program STRUCTURE (Gilbert et al. 2012), the proportion of studies with inadequate data or

311 metadata was similar to the current reanalysis (17 of 60 studies (28\%) in Gilbert et al., and 15 of

$31286(17 \%)$ here). The proportion of studies where we could not reproduce the analysis was also

313 broadly similar: 9 of 30 analyses (30\%) in Gilbert et al., and 12 of 71 studies (17\%) here. Despite

314 the somewhat lower percentage of successful reanalyses, the correlation between published and

315 reanalyzed results was consistently greater for DFA ( $r=0.94-0.96)$ than for STRUCTURE $(r=$

316 0.59). In attempts to reanalyse microarray data sets, which are much more complex than

317 morphological data sets, approximately half of the results could be reproduced from available

318 data (Ioannidis et al. 2009). It is not surprising that analyses with more steps and parameter

319 choices are harder to reproduce, and this is echoed within our study, where we had to explore a

320 wide range of analysis options to obtain close matches for the most complex DFA statistic, PAC.

321 At the same time, DFA represents a relatively simple, well documented scientific analysis, and it

322 is likely that complex analyses with more subcomponents, larger datasets, complex software

323 dependencies and a less objective decision process will require much more information

324 (metadata) to re-analyse and eventually reproduce. The wider adoption of metadata standards

325 like the Ecological Metadata Language (Michener et al 1997,

326 https://knb.ecoinformatics.org/\#tools) would go a long way towards ensuring that crucial details

327 about more complex datasets are not lost over time.

328 Shared data is an important substrate for science and is one of the levers that may be used to

329 improve the reliability of research (Ioannidis 2014). The system of having data re-users directly

330 contact data generators to obtain access to their data has been in place for decades, and is

331 absolutely necessary for data re-use within embargo periods (Roche et al. 2014), but it is not a

332 long-term solution for the preservation of research data (Vines et al. 2014). We argue that in 
333 order for archived data to retain their full value, all of the necessary data and metadata must be

334 stored at the time of archiving, which typically happens at or soon before/after publication. We

335 have determined some of the common problems that can occur in self-archived data even when

336 authors can be contacted and are able to share their data. The same factors are relevant to

337 communal data archives. While sequence repositories such as NCBI Genbank have made the

338 provision of metadata a key part of the submission, the decision of what additional information

339 to archive to more generalised databases such as Dryad, figshare, Zenodo or GitHub, lies with

340 the authors. The results presented here and those of previous studies (Savage \& Vickers 2009;

341 Gilbert et al. 2012; Drew et al. 2013; Vines et al. 2013; Vines et al. 2014) illustrate the need for

342 our research community to make data availability and curation a central part of the research and

343 publication process.

\section{Acknowledgments}

345 We are extremely grateful to the authors who kindly provided their data, without which this

346 research would not have been possible. We also thank our collaborators on the first part of this

347 project, Florence Débarre, Michelle Franklin, Kim Gilbert and Jean-Sébastien Moore. We thank

348 Michael Whitlock and Heather Piwowar for useful discussions during the planning of the project

349 and Mary O'Connor for thoughtful comments on our manuscript.

\section{References}

351 2013. Announcement: Reducing our irreproducibility. Nature. p 398.

352 Amado S, Armada-da-Silva PA, João F, Maurício AC, Luís AL, Simões MJ, and Veloso AP. 2011. The sensitivity of two-dimensional hindlimb joint kinematics analysis in assessing functional recovery in rats after sciatic nerve crush. Behavioural Brain Research 225:562-573.

Amini F, Zamini A, and Ahmadi M. 2007. Intergeneric hybridization between Kutum, Rutilus frisii kutum, and Bream, Abramis brama orientalis, of the Caspian Sea. Journal of the World Aquaculture Society 38:497-505. 
359

360

361

362

363

364

365

366

367

368

369

370

371

372

373

374

375

376

377

378

379

380

381

382

383

384

385

386

387

388

389

Aparicio E, García-Berthou E, Araguas R, Martínez P, and García-Marín J. 2005. Body pigmentation pattern to assess introgression by hatchery stocks in native Salmo trutta from Mediterranean streams. Journal of Fish Biology 67:931-949.

Armbrust M, Fox A, Griffith R, Joseph AD, Katz R, Konwinski A, Lee G, Patterson D, Rabkin A, Stoica I, and Zaharia M. 2010. A view of cloud computing. Communications of the ACM 53:50-58.

Asanidze Z, Akhalkatsi M, and Gvritishvili M. 2011. Comparative morphometric study and relationships between the Caucasian species of wild pear (Pyrus spp.) and local cultivars in Georgia. Flora-Morphology, Distribution, Functional Ecology of Plants 206:974-986.

Audisio P, Belfiore C, De Biase A, and Antonini G. 2001. Identification of Meligethes matronalis and M. subaeneus based on morphometric and ecological characters (Coleoptera: Nitidulidae). European Journal of Entomology 98:87-98.

Begley CG, and Ellis LM. 2012. Drug development: Raise standards for preclinical cancer research. Nature 483:531-533.

Berzins LL, Gilchrist HG, and Burness G. 2009. No assortative mating based on size in black guillemots breeding in the Canadian Arctic. Waterbirds 32:459-463.

Bolker B, and Phillips PC. 2012. cpcbp: common principal components/back-projection analysis. $\mathrm{R}$ package version 0.3.3.

Borer ET, Seabloom EW, Jones MB, and Schildhauer M. 2009. Some simple guidelines for effective data management. Bulletin of the Ecological Society of America 90:205-214.

Bourgeois K, Curé C, Legrand J, Gómez-Díaz E, Vidal E, Aubin T, and Mathevon N. 2007. Morphological versus acoustic analysis: what is the most efficient method for sexing yelkouan shearwaters Puffinus yelkouan? Journal of Ornithology 148:261-269.

Brysting A, Elven R, and Nordal I. 1997. The hypothesis of hybrid origin of Poa jemtlandica supported by morphometric and isoenzyme data. Nordic Journal of Botany 17:199-214.

Buczkó K, Wojtal AZ, and Jahn R. 2009. Kobayasialla species of the Carpathian region: morphology, taxonomy and description of K. tintinnus spec. nov. Diatom Research 24:121.

Bulgarella M, Wilson RE, Kopuchian C, Valqui TH, and McCracken KG. 2007. Elevational variation in body size of crested ducks (Lophonetta specularioides) from the central high Andes, Mendoza, and Patagonia. Ornitologia Neotropical 18:587-602. 
390

391

392

393

394

395

396

397

398

399

400

401

402

403

404

405

406

407

408

409

410

411

412

413

414

415

416

417

418 419

Burnaby TP. 1966. Growth-invariant discriminant functions and generalized distances. Biometrics 22:96-110.

Cadrin SX. 1995. Discrimination of American lobster (Homarus americanus) stocks off southern New England on the basis of secondary sex character allometry. Canadian Journal of Fisheries and Aquatic Sciences 52:2712-2723.

Capoccioni F, Costa C, Aguzzi J, Menesatti P, Lombarte A, and Ciccotti E. 2011. Ontogenetic and environmental effects on otolith shape variability in three Mediterranean European eel (Anguilla anguilla, L.) local stocks. Journal of Experimental Marine Biology and Ecology 397:1-7.

Cavalcanti MJ. 1999. LINDA — linear discriminant analysis and comparison of multivariate samples with randomisation tests. http://life.biosunysb.edu/morph/

Conde-Padín P, Grahame J, and Rolán-Alvarez E. 2007. Detecting shape differences in species of the Littorina saxatilis complex by morphometric analysis. Journal of Molluscan Studies 73:147-154.

Contrafatto G. 2005. Species with fuzzy borders: the taxonomic status and species limits of Saunders' vlei rat, Otomys saundersiae Roberts, 1929 (Rodentia, Muridae, Otomyini). Mammalia 69:297-322.

Darbyshire S, and Cayouette J. 1995. Identification of the species in the Panicum capillare complex (Poaceae) from eastern Canada and adjacent New York State. Canadian Journal of Botany 73:333-348.

de la Hera I, Pérez-Tris J, and Telleria JL. 2007. Testing the validity of discriminant function analyses based on bird morphology: the case of migratory and sedentary blackcaps Sylvia atricapilla wintering in southern Iberia. Ardeola 54:81-91.

Dechaume-Moncharmont F-X, Monceau K, and Cezilly F. 2011. Sexing birds using discriminant function analysis: a critical appraisal. The Auk 128:78-86.

Drew BT, Gazis R, Cabezas P, Swithers KS, Deng J, Rodriguez R, Katz LA, Crandall KA, Hibbett DS, and Soltis DE. 2013. Lost Branches on the Tree of Life. PLoS Biol 11:e1001636.

Ekrt L, Travnicek P, Jarolimova V, Vit P, and Urfus T. 2009. Genome size and morphology of the Dryopteris affinis group in Central Europe. Preslia 81:261-280. 
420 Errington TM, Iorns E, Gunn W, Tan FE, Lomax J, and Nosek BA. 2014. An open investigation

421

422

423

424

425

426

427

428

429

430

431

432

433

434

435

436

437

438

439

440

441

442

443

444

445

446

447

448

of the reproducibility of cancer biology research.

Eslami A, Qannari E, Bougeard S, and Sanchez G. 2014. multigroup: methods for multigroup data analysis. R package version 0.4.2. .

Fernández IÁ, and Feliner GN. 2001. A multivariate approach to assess the taxonomic utility of morphometric characters in Doronicum (Asteraceae, Senecioneae). Folia Geobotanica $36: 423-444$.

Fisher RA. 1936. The use of multiple measurements in taxonomic problems. Annals of Eugenics 7:179-188.

Floate KD, and Whitham TG. 1995. Insects as traits in plant systematics: their use in discriminating between hybrid cottonwoods. Canadian Journal of Botany 73:1-13.

Foggi B, Rossi G, and Signorini M. 1999. The Festuca violacea aggregate (Poaceae) in the Alps and Apennines (central southern Europe). Canadian Journal of Botany 77:989-1013.

Forster MA, Ladd B, and Bonser SP. 2010. Optimal allocation of resources in response to shading and neighbours in the heteroblastic species, Acacia implexa. Annals of Botany 107:219-228.

Gabrielson PW, Miller KA, and Martone PT. 2011. Morphometric and molecular analyses confirm two distinct species of Calliarthron (Corallinales, Rhodophyta), a genus endemic to the northeast Pacific. Phycologia 50:298-316.

Gilbert KJ, Andrew RL, Bock DG, Franklin MT, Kane NC, Moore J-S, Moyers BT, Renaut S, Rennison DJ, Veen T, and Vines TH. 2012. Recommendations for utilizing and reporting population genetic analyses: the reproducibility of genetic clustering using the program STRUCTURE. Molecular Ecology 21:4925-4930.

Ginoris Y, Amaral A, Nicolau A, Coelho M, and Ferreira E. 2007. Development of an image analysis procedure for identifying protozoa and metazoa typical of activated sludge system. Water Research 41:2581-2589.

Gordo FP, and Bandera CC. 1997. Differentiation of Spanish strains of Echinococcus granulosus using larval rostellar hook morphometry. International Journal for Parasitology 27:4149. 
449 Gouws G, Stewart BA, and Reavell PE. 2001. A new species of freshwater crab (Decapoda, 450 Potamonautidae) from the swamp forests of Kwazulu-Natal, South Africa: biochemical 451 and morphological evidence. Crustaceana 74:137-160.

452 Gugerli F. 1997. Hybridization of Saxifraga oppositifolia and S. biflora (Saxifragaceae) in a 453 mixed alpine population. Plant Systematics and Evolution 207:255-272.

Hata Y, Hashiba T, Nakamura T, Kitamura M, Ishida TA, Akimoto S-i, Sato H, and Kimura MT. 2011. Differences in leafminer (Phyllonorycter, Gracillariidae, Lepidoptera) and aphid (Tuberculatus, Aphididae, Hemiptera) composition among Quercus dentata, Q. crispula, Q. serrata, and their hybrids. Journal of Forest Research 16:309-318.

Hendriks IE, Van Duren LA, and Herman PM. 2005. Image analysis techniques: A tool for the identification of bivalve larvae? Journal of Sea Research 54:151-162.

Heraty JM, and Woolley JB. 1993. Separate species or polymorphism: a recurring problem in Kapala (Hymenoptera: Eucharitidae). Annals of the Entomological Society of America 86:517-531.

Hermida M, San Miguel E, Bouza C, Castro J, and Martínez P. 2009. Morphological variation in a secondary contact between divergent lineages of brown trout (Salmo trutta) from the Iberian Peninsula. Genetics and Molecular Biology 32:42-50.

Ibáñez AL, and O'Higgins P. 2011. Identifying fish scales: The influence of allometry on scale shape and classification. Fisheries Research 109:54-60.

Ioannidis JPA. 2014. How to make more published research true. PLoS Med 11:e1001747. Ioannidis JPA, Allison DB, Ball CA, Coulibaly I, Cui X, Culhane AC, Falchi M, Furlanello C, Game L, Jurman G, Mangion J, Mehta T, Nitzberg M, Page GP, Petretto E, and van Noort V. 2009. Repeatability of published microarray gene expression analyses. Nature Genetics 41:149-155.

Katoh M, and Tokimura M. 2001. Genetic and morphological identification of Sebastiscus tertius in the East China Sea (Scorpaeniformes: Scorpaenidae). Ichthyological Research 48:247-255.

López-González C, Presley SJ, Owen RD, and Willig MR. 2001. Taxonomic status of Myotis (Chiroptera: vespertilionidae) in Paraguay. Journal of Mammalogy 82:138-160. 
478 Magud BD, Stanisavljević LŽ, and Petanović RU. 2007. Morphological variation in different

479

480

481

482

483

484

485

486

487

488

489

490

491

492

493

494

495

496

497

498

499

500

501

502

503

504

505

506

507

508 populations of Aceria anthocoptes (Acari: Eriophyoidea) associated with the Canada thistle, Cirsium arvense, in Serbia. Experimental and Applied Acarology 42:173-183.

Malenke JR, Johnson KP, and Clayton DH. 2009. Host specialization differentiates cryptic species of feather-feeding lice. Evolution 63:1427-1438.

Marhold K, Jongepierová I, Krahulcová A, and Kucera J. 2005. Morphological and karyological differentiation of Gymnadenia densiflora and G. conopsea in the Czech Republic and Slovakia. Preslia 77:159-176.

McNutt M. 2014. Journals unite for reproducibility. Science 346:679.

Michener WK, Brunt JW, Helly JJ, Kirchner TB, and Stafford SG. 1997. Nongeospatial metadata for the ecological sciences. Ecological Applications 7:330-342.

Mills SC, and Côté IM. 2003. Sex-related differences in growth and morphology of blue mussels. Journal of the Marine Biological Association of the UK 83:1053-1057.

Nishida S, Naiki A, and Nishida T. 2005. Morphological variation in leaf domatia enables coexistence of antagonistic mites in Cinnamomum camphora. Canadian Journal of Botany 83:93-101.

Okuda N, Ito S, and Iwao H. 2003. Female mimicry in a freshwater goby Rhinogobius sp. OR. Ichthyological Research 50:198-200.

Palma L, Mira S, Cardia P, Beja P, Guillemaud T, Ferrand N, and Cancela ML. 2001. Sexing Bonelli's Eagle nestlings: Morphometrics versus molecular techniques. Journal of Raptor Research 35:187-193.

Parent GJ, Plourde S, and Turgeon J. 2011. Overlapping size ranges of Calanus spp. off the Canadian Arctic and Atlantic Coasts: impact on species' abundances. Journal of Plankton Research 33:1654-1665.

Pearce TA, Fields MC, and Kurita K. 2007. Discriminating shells of Gastrocopta pentodon (Say, 1822) and G. tappaniana (CB Adams, 1842)(Gastropoda: Pulmonata) with an example from the Delmarva Peninsula, eastern USA. Nautilus 121:66-75.

Pérez-Farrera MA, Vovides AP, Martinez-Camilo R, Melendez NM, and Iglesias C. 2009. A reassessment of the Ceratozamia miqueliana species complex (Zamiaceae) of southeastern Mexico, with comments on species relationships. Systematics and Biodiversity 7:433-443. 
509 Price M. 2011. To replicate or not to replicate? Science Careers.

510 R Core Development Team. 2011. R: A Language and Environment for Statistical Computing.

511 Version 3.1.0. Vienna, Austria: R Foundation for Statistical Computing.

512 R Core Team (2014). foreign: Read Data Stored by Minitab, S, SAS, SPSS, Stata, Systat, Weka,

513 dBase, ... R package version 0.8-61. http://CRAN.R-project.org/package=foreign

514 Radloff SE, Hepburn HR, Fuchs S, Otis GW, Hadisoesilo S, Hepburn C, and Ken T. 2005.

$515 \quad$ Multivariate morphometric analysis of the Apis cerana populations of oceanic Asia.

$516 \quad$ Apidologie 36:475.

517 Reyment RA, Blackith RE, and Campbell NR. 1984. Multivariate Morphometrics. London:

$518 \quad$ Academic Press.

519 Rigby MC, and Font WF. 2001. Statistical reanalysis of the distinction between Spirocamallanus istiblenni and S. monotaxis (Nematoda: Camallanidae). Journal of Parasitology 87:1210-

521 1213.

522

523

524

525

526

527

528

529

Ruedi M. 1995. Taxonomic revision of shrews of the genus Crocidura from the Sunda Shelf and Sulawesi with description of two new species (Mammalia: Soricidae). Zoological Journal of the Linnean Society 115:211-265.

Russell JC, Ringler D, Trombini A, and Le Corre M. 2011. The island syndrome and population 533 dynamics of introduced rats. Oecologia 167:667-676.

534 Salcedo N, Rodriguez D, Strauss R, and Baker R. 2011. The Fitzcarrald Arch: a vicariant event for Chaetostoma (Siluriformes: Loricariidae) speciation? Copeia 2011:503-512.

536 Santiago-Alarcon D, and Parker PG. 2007. Sexual size dimorphism and morphological evidence supporting the recognition of two subspecies in the Galápagos Dove. The Condor 109:132-141. 
539 Savage CJ, and Vickers AJ. 2009. Empirical Study of Data Sharing by Authors Publishing in

540

541

542

543

544

545

546

547

548

549

550

551

552

553

554

555

556

557

558

559

560

561

562

563

564

565

566

567

PLoS Journals. PLoS ONE 4:e7078.

Schagerl M, and Kerschbaumer M. 2009. Autecology and morphology of selected Vaucheria species (Xanthophyceae). Aquatic Ecology 43:295-303.

Semple JC, Chmielewski JG, and Leeder C. 1991. A multivariate morphometric study and revision of Aster subg. Doellingeria sect. Triplopappus (Compositae: Astereae): the Aster umbellatus complex. Canadian Journal of Botany 69:256-276.

Svagelj WS, and Quintana F. 2007. Sexual size dimorphism and sex determination by morphometric measurements in breeding imperial shags (Phalacrocorax atriceps). Waterbirds 30:97-102.

Thorogood R, Brunton D, and Castro I. 2009. Simple techniques for sexing nestling hihi (Notiomystis cincta) in the field. New Zealand Journal of Zoology 36:115-121.

Vanclay JK, Gillison AN, and Keenan RJ. 1997. Using plant functional attributes to quantify site productivity and growth patterns in mixed forests. Forest Ecology and Management 94:149-163.

Venables WN, and Ripley BD. 2002. Modern Applied Statistics with S. New York: Springer.

Vines Timothy H, Albert Arianne YK, Andrew Rose L, Débarre F, Bock Dan G, Franklin Michelle T, Gilbert Kimberly J, Moore J-S, Renaut S, and Rennison Diana J. 2014. The availability of research data declines rapidly with article age. Current Biology 24:94-97.

Vines TH, Andrew RL, Bock DG, Franklin MT, Gilbert KJ, Kane NC, Moore J-S, Moyers BT, Renaut S, Rennison DJ, Veen T, and Yeaman S. 2013. Mandated data archiving greatly improves access to research data. The FASEB Journal 27:1304-1308.

Wasowicz P, and Rostanski A. 2009. The use of quantitative characters in determination of frequently misdiagnosed species within Lepidium L. sect. Dileptium [Brassicaceae]. Acta Societatis Botanicorum Poloniae 78:221-227.

White EP, Baldridge E, Brym ZT, Locey KJ, McGlinn DJ, and Supp SR. 2013. Nine simple ways to make it easier to (re)use your data. Ideas in Ecology and Evolution 6:1-10.

Whitlock MC. 2011. Data archiving in ecology and evolution: best practices. Trends in Ecology \& Evolution 26:61-65. 
568 Wicherts JM, Bakker M, and Molenaar D. 2011. Willingness to Share Research Data Is Related

569

570

571

572

573

574

575

576

577

578

579

580

581

582

583

584 to the Strength of the Evidence and the Quality of Reporting of Statistical Results. PLoS ONE 6:e26828.

Wicherts JM, Borsboom D, Kats J, and Molenaar D. 2006. The poor availability of psychological research data for reanalysis. American Psychologist 61:726-728.

Wicht B, Moretti M, Preatoni D, Tosi G, and Martinoli A. 2003. The presence of Soprano pipistrelle Pipistrellus pygmaeus (Leach, 1825) in Switzerland: first molecular and bioacustic evidences. Revue Suisse de Zoologie 110:411-426.

Williams CT, Dean Kildaw S, and Loren Buck C. 2007. Sex-specific differences in body condition indices and seasonal mass loss in Tufted Puffins. Journal of Field Ornithology 78:369-378.

Wolkovich EM, Regetz J, and O'Connor MI. 2012. Advances in global change research require open science by individual researchers. Global Change Biology 18:2102-2110.

Zaitoun IS, Tabbaa MJ, and Bdour S. 2005. Differentiation of native goat breeds of Jordan on the basis of morphostructural characteristics. Small Ruminant Research 56:173-182. 


\section{Table $\mathbf{1}_{\text {(on next page) }}$}

Table 1

Summary of papers excluded from or included in the study, in total and listed by the statistical software originally used to analyse the data. Those included in the study are further broken down by the reasons that reanalysis was not attempted or by the results of the reanalysis. The reanalysis outcome was classified as a complete match when all reanalyzed summary statistics were within $1 \%$ of the published values, a partial match when at least one (but not all) met this criterion, and no match when none met this criterion. The metrics considered were PVE, a discriminant function coefficient, and PAC. 


\section{Tables}

2 Table 1. Summary of papers excluded from or included in the study, in total and listed by the statistical software originally used to 3 analyse the data. Those included in the study are further broken down by the reasons that reanalysis was not attempted or by the

4 results of the reanalysis. The reanalysis outcome was classified as a complete match when all reanalyzed summary statistics were

5 within $1 \%$ of the published values, a partial match when at least one (but not all) met this criterion, and no match when none met this

6 criterion. The metrics considered were PVE, a discriminant function coefficient, and PAC.

\begin{tabular}{lcccccccc}
\multicolumn{1}{c}{ Software } & Excluded & Included & $\begin{array}{c}\text { Incorrect } \\
\text { data file }\end{array}$ & $\begin{array}{c}\text { Insufficient } \\
\text { metadata }\end{array}$ & $\begin{array}{c}\text { Data } \\
\text { discrepancy }\end{array}$ & No match & $\begin{array}{c}\text { Reanalysed } \\
\text { Partial match }\end{array}$ & Complete match \\
TOTAL & 14 & 86 & $2(2.3 \%)$ & $7(8.1 \%)$ & $7(8.1 \%)$ & $12(14 \%)$ & $46(53.5 \%)$ & $12(14 \%)$ \\
JMP & 2 & 2 & $0(0 \%)$ & $1(50 \%)$ & $0(0 \%)$ & $0(0 \%)$ & $0(0 \%)$ & $1(50 \%)$ \\
MATLAB & 1 & 2 & $0(0 \%)$ & $0(0 \%)$ & $1(50 \%)$ & $0(0 \%)$ & $0(0 \%)$ & $1(50 \%)$ \\
R & 0 & 5 & $2(40 \%)$ & $0(0 \%)$ & $1(20 \%)$ & $1(20 \%)$ & $0(0 \%)$ & $1(20 \%)$ \\
SAS & 1 & 15 & $0(0 \%)$ & $3(20 \%)$ & $2(13 \%)$ & $3(20 \%)$ & $2(13 \%)$ & $5(33 \%)$ \\
SPSS & 6 & 30 & $0(0 \%)$ & $0(0 \%)$ & $2(7 \%)$ & $5(17 \%)$ & $6(20 \%)$ & $17(57 \%)$ \\
STATISTICA & 0 & 9 & $0(0 \%)$ & $1(11 \%)$ & $1(11 \%)$ & $2(22 \%)$ & $0(0 \%)$ & $5(56 \%)$ \\
SYSTAT & 0 & 8 & $0(0 \%)$ & $0(0 \%)$ & $0(0 \%)$ & $1(12 \%)$ & $2(25 \%)$ & $5(62 \%)$ \\
Other & 1 & 2 & $0(0 \%)$ & $1(50 \%)$ & $0(0 \%)$ & $0(0 \%)$ & $0(0 \%)$ & $1(50 \%)$ \\
Unknown & 3 & 13 & $0(0 \%)$ & $1(8 \%)$ & $0(0 \%)$ & $0(0 \%)$ & $2(15 \%)$ & $10(77 \%)$
\end{tabular}




\section{Table 2 (on next page)}

Table 2.

Published results and reanalyzed values of DFAs based on data files received from authors. DFAs included in the current study were categorized according to the adequacy of data files and metadata, and the reproducibility of three metrics (percent variance explained, the largest coefficient and percent assigned correctly) among those that were able to be reanalyzed. Category indicates whether the data set was excluded from the study $(E)$, was incorrect (I), had inadequate metadata (M), displayed data discrepancies (D) or was reanalysed (R). The reasons for excluding data sets from the study or preventing us from reanalyzing the data are summarized. The reanalysis outcome was classified as a complete match $(\mathrm{C})$ when all reanalyzed summary statistics were within $1 \%$ of the published values, a partial match (P) when at least one (but not all) met this criterion, and no match ( $N$ ) when none met this criterion. The same classification was applied to studies using the 'close' criterion (within 5\%). 
Table 2. Published results and reanalyzed values of DFAs based on data files received from authors. DFAs included in the current study were categorized according to the adequacy of data files and metadata, and the reproducibility of three metrics (percent variance explained, the largest coefficient and percent assigned correctly) among those that were able to be reanalyzed. Category indicates whether the data set was excluded from the study (E), was incorrect (I), had inadequate metadata (M), displayed data discrepancies (D) or was reanalysed (R). The reasons for excluding data sets from the study or preventing us from reanalyzing the data are summarized. The reanalysis outcome was classified as a complete match $(\mathrm{C})$ when all reanalyzed summary statistics were within $1 \%$ of the published values, a partial match $(\mathrm{P})$ when at least one (but not all) met this criterion, and no match $(\mathrm{N})$ when none met this criterion. The same classification was applied to studies using the 'close' criterion (within 5\%).

\begin{tabular}{|c|c|c|c|c|c|c|c|c|c|c|c|c|c|}
\hline \multirow{2}{*}{$\begin{array}{l}\text { Stud } \\
\text { y no. }\end{array}$} & \multirow[t]{2}{*}{ Year } & \multirow[t]{2}{*}{ Software } & \multicolumn{2}{|c|}{ PVE } & \multicolumn{2}{|c|}{ COEF } & \multicolumn{2}{|c|}{ PAC } & \multirow{2}{*}{ Categ. } & \multirow[t]{2}{*}{ Reason } & \multicolumn{2}{|c|}{ Reanalysis outcome } & \multirow[t]{2}{*}{ Citation* } \\
\hline & & & $\begin{array}{c}\text { Publishe } \\
\text { d }\end{array}$ & Reanalyzed & Published & Reanalyzed & Published & Reanalyzed & & & $\begin{array}{c}\text { Match } \\
\text { (within } \\
1 \% \text { ) }\end{array}$ & $\begin{array}{c}\text { Close } \\
\text { (within } \\
5 \% \text { ) }\end{array}$ & \\
\hline 1 & 1991 & SAS & 47.3 & 45.8 & & & 93.2 & 93.2 & $\mathrm{R}$ & & $\mathrm{P}$ & $\mathrm{C}$ & (Semple et al. 1991) \\
\hline 2 & 1993 & SAS & 83.2 & 84.2 & 18.94 & 20.609 & & & $\mathrm{R}$ & & $\mathrm{N}$ & $\mathrm{P}$ & $\begin{array}{c}\text { (Heraty \& Woolley } \\
1993)\end{array}$ \\
\hline 3 & 1995 & $\begin{array}{c}\text { Other } \\
\text { (STATGRA } \\
\text { PHICS) }\end{array}$ & 79.1 & 79.1 & 2.87 & -2.868 & 72 & 71.9 & $\mathrm{R}$ & & $\mathrm{C}$ & $\mathrm{C}$ & $\begin{array}{c}\text { (Darbyshire \& } \\
\text { Cayouette 1995) }\end{array}$ \\
\hline 4 & 1995 & SPSS & & & 0.892 & 0.7 & 100 & 100 & $\mathrm{R}$ & & $\mathrm{P}$ & $\mathrm{P}$ & (Cadrin 1995) \\
\hline 5 & 1995 & SPSS & 57.3 & 57.3 & & & 91.4 & 91.4 & $\mathrm{R}$ & & $\mathrm{C}$ & $\mathrm{C}$ & \\
\hline 6 & 1995 & SPSS & & & 4.02 & -3.805 & 100 & 100 & $\mathrm{R}$ & & $\mathrm{P}$ & $\mathrm{P}$ & (Ruedi 1995) \\
\hline 7 & 1995 & SYSTAT & & & -1.09 & 1.091 & 92 & 86.9 & $\mathrm{R}$ & & $\mathrm{P}$ & $\mathrm{P}$ & \\
\hline 8 & 1995 & SYSTAT & & & 2.115 & -2.115 & 100 & 100 & $\mathrm{R}$ & & $\mathrm{C}$ & $\mathrm{C}$ & $\begin{array}{c}\text { (Floate \& Whitham } \\
1995)\end{array}$ \\
\hline 9 & 1997 & Not stated & & & & & & & $\mathrm{E}$ & $\begin{array}{l}\text { Not all variables are } \\
\text { morphological }\end{array}$ & & & (Vanclay et al. 1997) \\
\hline 10 & 1997 & SPSS & 67 & 66.9 & & & & & $\mathrm{R}$ & & $\mathrm{C}$ & $\mathrm{C}$ & (Brysting et al. 1997) \\
\hline 11 & 1997 & SPSS & 96.7 & 92.6 & 1.5 & -2.488 & 100 & 98.6 & $\mathrm{R}$ & & $\mathrm{N}$ & $\mathrm{P}$ & $\begin{array}{c}\text { (Gordo \& Bandera } \\
1997)\end{array}$ \\
\hline 12 & 1997 & SYSTAT & 99.5 & 99 & -0.57 & 0.611 & 89 & 88.7 & $\mathrm{R}$ & & $\mathrm{P}$ & $\mathrm{P}$ & (Gugerli 1997) \\
\hline 13 & 1999 & Not stated & & & & & & & M & $\begin{array}{l}\text { Row groupings don't } \\
\text { match paper }\end{array}$ & & & \\
\hline 14 & 1999 & Not stated & & & & & & & $\mathrm{E}$ & No PVE, coef. or & & & \\
\hline
\end{tabular}




\begin{tabular}{|c|c|c|c|c|c|c|c|c|c|c|c|c|c|}
\hline \multirow{2}{*}{$\begin{array}{l}\text { Stud } \\
\text { y no. }\end{array}$} & \multirow[t]{2}{*}{ Year } & \multirow[t]{2}{*}{ Software } & \multicolumn{2}{|c|}{ PVE } & \multicolumn{2}{|c|}{ COEF } & \multicolumn{2}{|c|}{ PAC } & \multirow{2}{*}{ Categ. } & \multirow[t]{2}{*}{ Reason } & \multicolumn{2}{|c|}{ Reanalysis outcome } & \multirow[t]{2}{*}{ Citation* } \\
\hline & & & $\begin{array}{l}\text { Publishe } \\
\text { d }\end{array}$ & Reanalyzed & Published & Reanalyzed & Published & Reanalyzed & & & $\begin{array}{c}\text { Match } \\
\text { (within } \\
1 \% \text { ) }\end{array}$ & $\begin{array}{l}\text { Close } \\
\text { (within } \\
5 \% \text { ) }\end{array}$ & \\
\hline & & & & & & & & & & PAC & & & \\
\hline 15 & 1999 & SAS & 65 & 64.2 & & & 61 & 61.4 & $\mathrm{R}$ & & $\mathrm{P}$ & $\mathrm{C}$ & \\
\hline 16 & 1999 & SPSS & & & & & & & $\mathrm{E}$ & $\begin{array}{l}\text { No PVE, coef. or } \\
\text { PAC }\end{array}$ & & & \\
\hline 17 & 1999 & SPSS & & & & & 73.4 & 73.4 & $\mathrm{R}$ & & $\mathrm{C}$ & $\mathrm{C}$ & \\
\hline 18 & 1999 & SYSTAT & & & & & 90 & 91.7 & $\mathrm{R}$ & & $\mathrm{N}$ & $\mathrm{C}$ & \\
\hline 19 & 2001 & Not stated & & & & & 100 & 100 & $\mathrm{R}$ & & $\mathrm{C}$ & $\mathrm{C}$ & (Rigby \& Font 2001) \\
\hline 20 & 2001 & SAS & 96.7 & 96.4 & & & & & $\mathrm{R}$ & & $\mathrm{C}$ & $\mathrm{C}$ & \\
\hline 21 & 2001 & SAS & & & & & 71.3 & 93.8 & $\mathrm{R}$ & & $\mathrm{N}$ & $\mathrm{N}$ & \\
\hline 22 & 2001 & SPSS & & & -1.072 & -1.072 & 96 & 100 & $\mathrm{R}$ & & $\mathrm{P}$ & $\mathrm{C}$ & (Palma et al. 2001) \\
\hline 23 & 2001 & SPSS & & & & & 100 & 100 & $\mathrm{R}$ & & $\mathrm{C}$ & $\mathrm{C}$ & \\
\hline 24 & 2001 & SPSS & 96 & 96 & & & & & $\mathrm{R}$ & & $\mathrm{C}$ & $\mathrm{C}$ & $\begin{array}{c}\text { (Fernández \& Feliner } \\
\text { 2001) }\end{array}$ \\
\hline 25 & 2001 & SPSS & & & 5.228 & -5.228 & 86 & 82.6 & $\mathrm{R}$ & & $\mathrm{P}$ & $\mathrm{C}$ & $\begin{array}{c}\text { (Katoh \& Tokimura } \\
\text { 2001) }\end{array}$ \\
\hline 26 & 2001 & $\begin{array}{l}\text { STATISTI } \\
\text { CA }\end{array}$ & & & & & 94.4 & 94.4 & $\mathrm{R}$ & & $\mathrm{C}$ & $\mathrm{C}$ & \\
\hline 27 & 2003 & Not stated & & & & & 90.3 & 90.3 & $\mathrm{R}$ & & $\mathrm{C}$ & $\mathrm{C}$ & (Okuda et al. 2003) \\
\hline 28 & 2003 & Not stated & & & -2.176 & -2.176 & 90.6 & 90.6 & $\mathrm{R}$ & & $\mathrm{C}$ & $\mathrm{C}$ & \\
\hline 29 & 2003 & SAS & & & & & & & M & $\begin{array}{l}\text { Column labels in } \\
\text { Spanish }\end{array}$ & & & \\
\hline 30 & 2003 & SAS & & & & & & & $\mathrm{D}$ & Extra rows & & & \\
\hline 31 & 2003 & SPSS & & & 1.011 & 1.011 & 100 & 100 & $\mathrm{R}$ & & $\mathrm{C}$ & $\mathrm{C}$ & \\
\hline 32 & 2003 & SPSS & & & 3.5 & & 81 & & $\mathrm{D}$ & Extra rows & & & (Mills \& Côté 2003) \\
\hline 33 & 2003 & SPSS & & & & & & & $\mathrm{D}$ & $\begin{array}{l}\text { Missing rows and } \\
\text { row assignments } \\
\text { unclear }\end{array}$ & & & \\
\hline 34 & 2003 & SPSS & & & & & 88.9 & 87.5 & $\mathrm{R}$ & & $\mathrm{N}$ & $\mathrm{C}$ & \\
\hline 35 & 2003 & SPSS & & & 0.772 & 0.766 & 84.3 & 84.3 & $\mathrm{R}$ & & $\mathrm{C}$ & $\mathrm{C}$ & \\
\hline 36 & 2003 & $\begin{array}{l}\text { STATISTI } \\
\text { CA }\end{array}$ & & & & & & & M & $\begin{array}{l}\text { Column labels } \\
\text { unclear }\end{array}$ & & & \\
\hline 37 & 2003 & SYSTAT & & & 1.28 & -1.275 & 81 & 80.6 & $\mathrm{R}$ & & $\mathrm{C}$ & $\mathrm{C}$ & (Wicht et al. 2003) \\
\hline 38 & 2005 & JMP & & & & & & & $\mathrm{E}$ & $\begin{array}{l}\text { No PVE, coef or } \\
\text { PAC }\end{array}$ & & & (Nishida et al. 2005) \\
\hline 39 & 2005 & Not stated & & & & & 79.9 & 79.7 & $\mathrm{R}$ & & $\mathrm{C}$ & $\mathrm{C}$ & (Hendriks et al. 2005) \\
\hline 40 & 2005 & Not stated & 83 & 83.1 & & & 73 & 74.3 & $\mathrm{R}$ & & $\mathrm{P}$ & $\mathrm{C}$ & \\
\hline 41 & 2005 & Not stated & & & & & 100 & 100 & $\mathrm{R}$ & & $\mathrm{C}$ & $\mathrm{C}$ & (Radloff et al. 2005) \\
\hline
\end{tabular}




\begin{tabular}{|c|c|c|c|c|c|c|c|c|c|c|c|c|c|}
\hline 44 & 2005 & SAS & & & & & & & M & $\begin{array}{l}\text { Column labels } \\
\text { missing }\end{array}$ & & & (Zaitoun et al. 2005) \\
\hline 45 & 2005 & SAS & & & & & 94.3 & 94.9 & $\mathrm{R}$ & & $\mathrm{C}$ & $\mathrm{C}$ & (Marhold et al. 2005) \\
\hline 46 & 2005 & SPSS & & & & & 46 & 38.2 & $\mathrm{R}$ & & $\mathrm{N}$ & $\mathrm{N}$ & (Aparicio et al. 2005) \\
\hline 47 & 2005 & SPSS & 55.1 & 55.6 & 0.352 & 0.779 & 71.8 & 70.3 & $\mathrm{R}$ & & $\mathrm{P}$ & $\mathrm{P}$ & \\
\hline 48 & 2005 & $\begin{array}{c}\text { STATISTI } \\
\text { CA }\end{array}$ & 67.5 & 67 & & & & & $\mathrm{R}$ & & $\mathrm{C}$ & $\mathrm{C}$ & \\
\hline 49 & 2005 & $\begin{array}{c}\text { STATISTI } \\
\text { CA }\end{array}$ & & & & & 97 & 98.8 & $\mathrm{R}$ & & $\mathrm{N}$ & $\mathrm{C}$ & \\
\hline 50 & 2005 & SYSTAT & & & & & 100 & 100 & $\mathrm{R}$ & & $\mathrm{C}$ & $\mathrm{C}$ & \\
\hline 51 & 2007 & MATLAB & & & & & & & $\mathrm{D}$ & $\begin{array}{l}\text { Missing columns and } \\
\text { insufficient metadata }\end{array}$ & & & \\
\hline 52 & 2007 & Not stated & & & 1.1 & 1.097 & 97 & 96.6 & $\mathrm{R}$ & & $\mathrm{C}$ & $\mathrm{C}$ & $\begin{array}{c}\text { (Svagelj \& Quintana } \\
\text { 2007) }\end{array}$ \\
\hline 53 & 2007 & Not stated & & & & & 87.9 & 87.9 & $\mathrm{R}$ & & $\mathrm{C}$ & $\mathrm{C}$ & $\begin{array}{c}\text { (de la Hera et al. } \\
\text { 2007) }\end{array}$ \\
\hline 54 & 2007 & SAS & & & 8.623 & 3.495 & 97.3 & 98.6 & $\mathrm{R}$ & & $\mathrm{N}$ & $\mathrm{P}$ & \\
\hline 55 & 2007 & SAS & & & & & 76 & 76.6 & $\mathrm{R}$ & & $\mathrm{C}$ & $\mathrm{C}$ & (Williams et al. 2007) \\
\hline 56 & 2007 & SAS & & & & & & & $\mathrm{D}$ & Missing columns & & & (Pearce et al. 2007) \\
\hline 57 & 2007 & SPSS & & & & & & & $\mathrm{E}$ & $\begin{array}{l}\text { No PVE, coef or } \\
\text { PAC }\end{array}$ & & & \\
\hline 58 & 2007 & SPSS & & & & & 76.9 & 76.9 & $\mathrm{R}$ & & $\mathrm{C}$ & $\mathrm{C}$ & $\begin{array}{l}\text { (Rioux-Paquette \& } \\
\text { Lapointe 2007) }\end{array}$ \\
\hline 59 & 2007 & SPSS & & & 0.689 & 0.647 & 100 & 85.4 & $\mathrm{R}$ & & $\mathrm{N}$ & $\mathrm{N}$ & $\begin{array}{c}\text { (Santiago-Alarcon \& } \\
\text { Parker 2007) }\end{array}$ \\
\hline 60 & 2007 & SPSS & 61.8 & 61.6 & & & & & $\mathrm{R}$ & & $\mathrm{C}$ & $\mathrm{C}$ & \\
\hline 61 & 2007 & SPSS & & & & & & & $\mathrm{E}$ & $\begin{array}{l}\text { Final model not } \\
\text { given }\end{array}$ & & & $\begin{array}{c}\text { (Conde-Padín et al. } \\
\text { 2007) }\end{array}$ \\
\hline 62 & 2007 & SPSS & & & & & 84 & 83.3 & $\mathrm{R}$ & & $\mathrm{C}$ & $\mathrm{C}$ & \\
\hline 63 & 2007 & $\begin{array}{l}\text { STATISTI } \\
\text { CA }\end{array}$ & & & & & 96.1 & 96.2 & $\mathrm{R}$ & & $\mathrm{C}$ & $\mathrm{C}$ & \\
\hline 64 & 2007 & $\begin{array}{c}\text { STATISTI } \\
\text { CA }\end{array}$ & 93.3 & 93.3 & -0.951 & -0.951 & 89.2 & 89.2 & $\mathrm{R}$ & & $\mathrm{C}$ & $\mathrm{C}$ & \\
\hline 65 & 2007 & STATISTI & & & 1.68 & 1.678 & 83.7 & 83.7 & $\mathrm{R}$ & & $\mathrm{C}$ & $\mathrm{C}$ & (Bourgeois et al. \\
\hline
\end{tabular}




\begin{tabular}{|c|c|c|c|c|c|c|c|c|c|c|c|c|c|}
\hline \multirow{2}{*}{$\begin{array}{l}\text { Stud } \\
\text { y no. }\end{array}$} & \multirow[t]{2}{*}{ Year } & \multirow[t]{2}{*}{ Software } & \multicolumn{2}{|c|}{ PVE } & \multicolumn{2}{|c|}{ COEF } & \multicolumn{2}{|c|}{ PAC } & \multirow[t]{2}{*}{ Categ. } & \multirow[t]{2}{*}{ Reason } & \multicolumn{2}{|c|}{ Reanalysis outcome } & \multirow[t]{2}{*}{ Citation* } \\
\hline & & & $\begin{array}{c}\text { Publishe } \\
\text { d }\end{array}$ & Reanalyzed & Published & Reanalyzed & Published & $\overline{\text { Reanalyzed }}$ & & & $\begin{array}{c}\text { Match } \\
\text { (within } \\
1 \% \text { ) }\end{array}$ & $\begin{array}{c}\text { Close } \\
\text { (within } \\
5 \% \text { ) }\end{array}$ & \\
\hline & & $\mathrm{CA}$ & & & & & & & & & & & 2007) \\
\hline 66 & 2007 & SYSTAT & 90.4 & 90.4 & & & 90 & 90 & $\mathrm{R}$ & & $\mathrm{C}$ & $\mathrm{C}$ & \\
\hline 67 & 2009 & Not stated & & & & & 91.2 & 91.2 & $\mathrm{R}$ & & $\mathrm{C}$ & $\mathrm{C}$ & \\
\hline 68 & 2009 & Not stated & & & & & & & $\mathrm{E}$ & Not DFA & & & \\
\hline 69 & 2009 & Not stated & 40.8 & 41.1 & & & 79 & 78.3 & $\mathrm{R}$ & & $\mathrm{C}$ & $\mathrm{C}$ & (Hermida et al. 2009) \\
\hline 70 & 2009 & Not stated & & & 0.242 & 0.084 & 100 & 100 & $\mathrm{R}$ & & $\mathrm{P}$ & $\mathrm{P}$ & (Buczkó et al. 2009) \\
\hline 71 & 2009 & SAS & 69 & 69.2 & 1.05 & -1.053 & & & $\mathrm{R}$ & & $\mathrm{C}$ & $\mathrm{C}$ & $\begin{array}{c}\text { (Pérez-Farrera et al. } \\
\text { 2009) }\end{array}$ \\
\hline 72 & 2009 & SAS & & & 0.95 & 0.604 & 80 & 80 & $\mathrm{R}$ & & $\mathrm{P}$ & $\mathrm{P}$ & \\
\hline 73 & 2009 & SPSS & & & & & 100 & 100 & $\mathrm{R}$ & & $\mathrm{C}$ & $\mathrm{C}$ & \\
\hline 74 & 2009 & SPSS & & & & & & & $\mathrm{E}$ & $\begin{array}{l}\text { Data not } \\
\text { morphological }\end{array}$ & & & \\
\hline 75 & 2009 & SPSS & & & & & 76.4 & 77 & $\mathrm{R}$ & & $\mathrm{C}$ & $\mathrm{C}$ & $\begin{array}{c}\text { (Thorogood et al. } \\
\text { 2009) }\end{array}$ \\
\hline 76 & 2009 & $\begin{array}{l}\text { STATISTI } \\
\text { CA }\end{array}$ & & & & & & & $\mathrm{D}$ & Missing rows & & & \\
\hline 77 & 2009 & $\begin{array}{l}\text { STATISTI } \\
\text { CA }\end{array}$ & & & & & 100 & 98.1 & $\mathrm{R}$ & & $\mathrm{N}$ & $\mathrm{C}$ & \\
\hline 78 & 2009 & SYSTAT & & & 2.8 & 2.795 & 91 & 91.5 & $\mathrm{R}$ & & $\mathrm{C}$ & $\mathrm{C}$ & (Berzins et al. 2009) \\
\hline 79 & 2011 & JMP & & & & & & & $\mathrm{E}$ & $\begin{array}{l}\text { No PVE, coef or } \\
\text { PAC }\end{array}$ & & & (Hata et al. 2011) \\
\hline 80 & 2011 & JMP & & & & & & & M & $\begin{array}{l}\text { Column labels } \\
\text { unclear }\end{array}$ & & & \\
\hline 81 & 2011 & JMP & & & -7.06 & 7.063 & 100 & 100 & $\mathrm{R}$ & & $\mathrm{C}$ & $\mathrm{C}$ & $\begin{array}{c}\text { (Gabrielson et al. } \\
\text { 2011) }\end{array}$ \\
\hline 82 & 2011 & MATLAB & 65.5 & 65 & & & & & $\mathrm{R}$ & & $\mathrm{C}$ & $\mathrm{C}$ & (Salcedo et al. 2011) \\
\hline 83 & 2011 & MATLAB & & & & & & & $\mathrm{E}$ & Not classical DFA & & & $\begin{array}{l}\text { (Capoccioni et al. } \\
\text { 2011) }\end{array}$ \\
\hline 84 & 2011 & Not stated & 90 & 90.5 & & & & & $\mathrm{R}$ & & $\mathrm{C}$ & $\mathrm{C}$ & (Russell et al. 2011) \\
\hline 85 & 2011 & $\mathrm{R}$ & & & & & & & $\mathrm{D}$ & Missing rows & & & \\
\hline 86 & 2011 & $\mathrm{R}$ & & & & & & & I & Wrong file & & & \\
\hline 87 & 2011 & $\mathrm{R}$ & & & & & & & $\mathrm{I}$ & Wrong file & & & \\
\hline 88 & 2011 & $\mathrm{R}$ & 58 & 88.3 & & & 56 & 57.1 & $\mathrm{R}$ & & $\mathrm{N}$ & $\mathrm{P}$ & \\
\hline 89 & 2011 & $\mathrm{R}$ & & & & & 80.4 & 80.4 & $\mathrm{R}$ & & $\mathrm{C}$ & $\mathrm{C}$ & $\begin{array}{c}\text { (Dechaume- } \\
\text { Moncharmont et al. } \\
\text { 2011) }\end{array}$ \\
\hline 90 & 2011 & SAS & & & & & & & $\mathrm{E}$ & Spanish & & & \\
\hline 91 & 2011 & SAS & & & & & 100 & 100 & $\mathrm{R}$ & & $\mathrm{C}$ & $\mathrm{C}$ & (Parent et al. 2011) \\
\hline
\end{tabular}




\begin{tabular}{|c|c|c|c|c|c|c|c|c|c|c|c|c|c|}
\hline \multirow{2}{*}{$\begin{array}{l}\text { Stud } \\
\text { y no. }\end{array}$} & \multirow[t]{2}{*}{ Year } & \multirow[t]{2}{*}{ Software } & \multicolumn{2}{|c|}{ PVE } & \multicolumn{2}{|c|}{ COEF } & \multicolumn{2}{|c|}{ PAC } & \multirow[t]{2}{*}{ Categ. } & \multirow[t]{2}{*}{ Reason } & \multicolumn{2}{|c|}{ Reanalysis outcome } & \multirow[t]{2}{*}{ Citation* } \\
\hline & & & $\begin{array}{c}\text { Publishe } \\
\text { d }\end{array}$ & Reanalyzed & Published & Reanalyzed & Published & Reanalyzed & & & $\begin{array}{c}\text { Match } \\
\text { (within } \\
1 \% \text { ) }\end{array}$ & $\begin{array}{c}\text { Close } \\
\text { (within } \\
5 \% \text { ) }\end{array}$ & \\
\hline 92 & 2011 & SPSS & 81.8 & 81.7 & & & & & $\mathrm{R}$ & & $\mathrm{C}$ & $\mathrm{C}$ & (Forster et al. 2010) \\
\hline 93 & 2011 & SPSS & 97.7 & 97.7 & & & 87.5 & 87.5 & $\mathrm{R}$ & & $\mathrm{C}$ & $\mathrm{C}$ & (Amado et al. 2011) \\
\hline 94 & 2011 & SPSS & 58.3 & 58.3 & & & 62.9 & 62.9 & $\mathrm{R}$ & & $\mathrm{C}$ & $\mathrm{C}$ & $\begin{array}{c}\text { (Ibáñez \& O’Higgins } \\
2011)\end{array}$ \\
\hline 95 & 2011 & SPSS & 87.7 & 87.5 & & & & & $\mathrm{R}$ & & $\mathrm{C}$ & $\mathrm{C}$ & \\
\hline 96 & 2011 & SPSS & & & & & & & $\mathrm{E}$ & $\begin{array}{l}\text { Final model not } \\
\text { given }\end{array}$ & & & \\
\hline 97 & 2011 & SPSS & & & & & & & $\mathrm{E}$ & $\begin{array}{l}\text { Final model not } \\
\text { given }\end{array}$ & & & (Asanidze et al. 2011) \\
\hline 98 & 2011 & SPSS & & & & & 100 & 100 & $\mathrm{R}$ & & $\mathrm{C}$ & $\mathrm{C}$ & \\
\hline 99 & 2011 & SPSS & & & & & 95.7 & 93.9 & $\mathrm{R}$ & & $\mathrm{N}$ & $\mathrm{C}$ & \\
\hline 100 & 2011 & SPSS & 96 & 89.7 & 1.202 & 0.068 & 100 & 100 & $\mathrm{R}$ & & $\mathrm{P}$ & $\mathrm{P}$ & \\
\hline
\end{tabular}

9

10 *Authors were contacted individually once reanalyses were performed. Only authors wishing to be identified are cited above. In

11 addition, several authors agreed to be cited, but not identified directly (Amini et al. 2007; Audisio et al. 2001; Bulgarella et al. 2007;

12 Ekrt et al. 2009; Foggi et al. 1999; Ginoris et al. 2007; Gouws et al. 2001; López-González et al. 2001; Magud et al. 2007; Malenke et

13 al. 2009; Schagerl \& Kerschbaumer 2009; Wasowicz \& Rostanski 2009) 


\section{Figure $\mathbf{1}$ (on next page)}

\section{Figure 1}

Summary of the reproducibility of the 71 reanalyzed data sets and of the problems preventing reanalysis of 15 papers (see Table 1 ). 


\section{Eligible data sets 86 studies

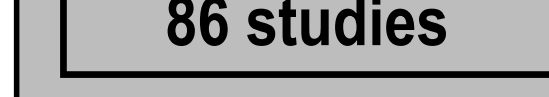

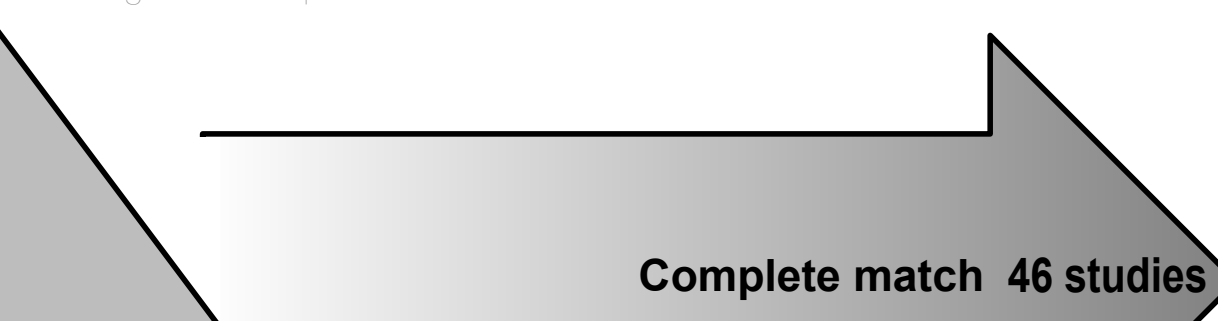




\section{Figure 2 (on next page)}

Figure 2

PVE values from reanalysis versus published DFA. Points on the 1:1 line represent analyses differing by $1 \%$ or less. 
PeerJ Reviewing Manuscript

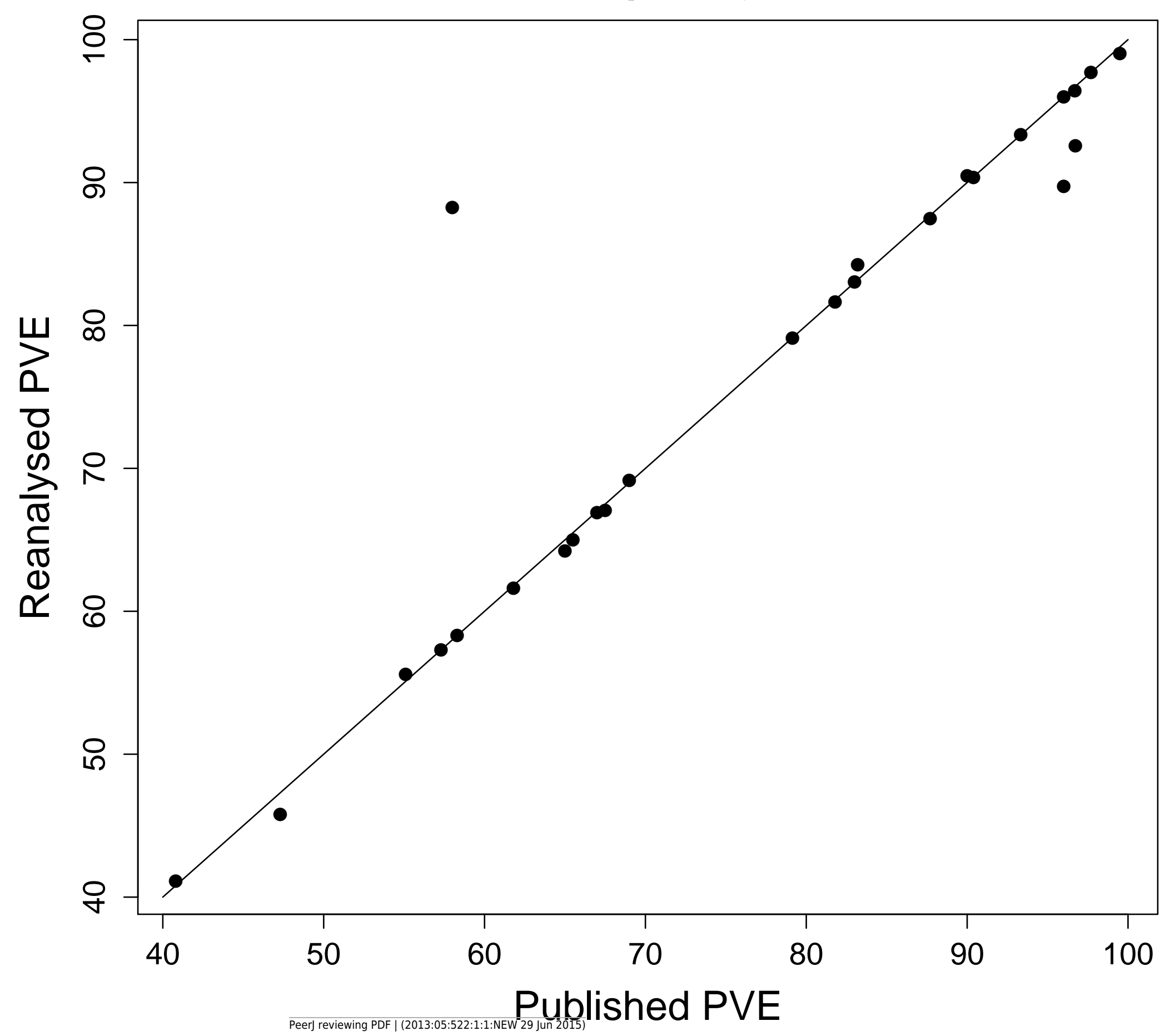




\section{Figure 3 (on next page)}

Figure 3

PAC values from reanalysis versus published DFA. Points on the 1:1 line represent analyses differing by $1 \%$ or less. 
Figure 4 (on next page)

Figure 4

Discriminant function coefficients from the reanalysis versus the published results. Absolute values are used because the signs of coefficients depends on the order of variables. Points on the $1: 1$ line represent analyses differing by $1 \%$ or less. 
PeerJ Reviewing Manuscript

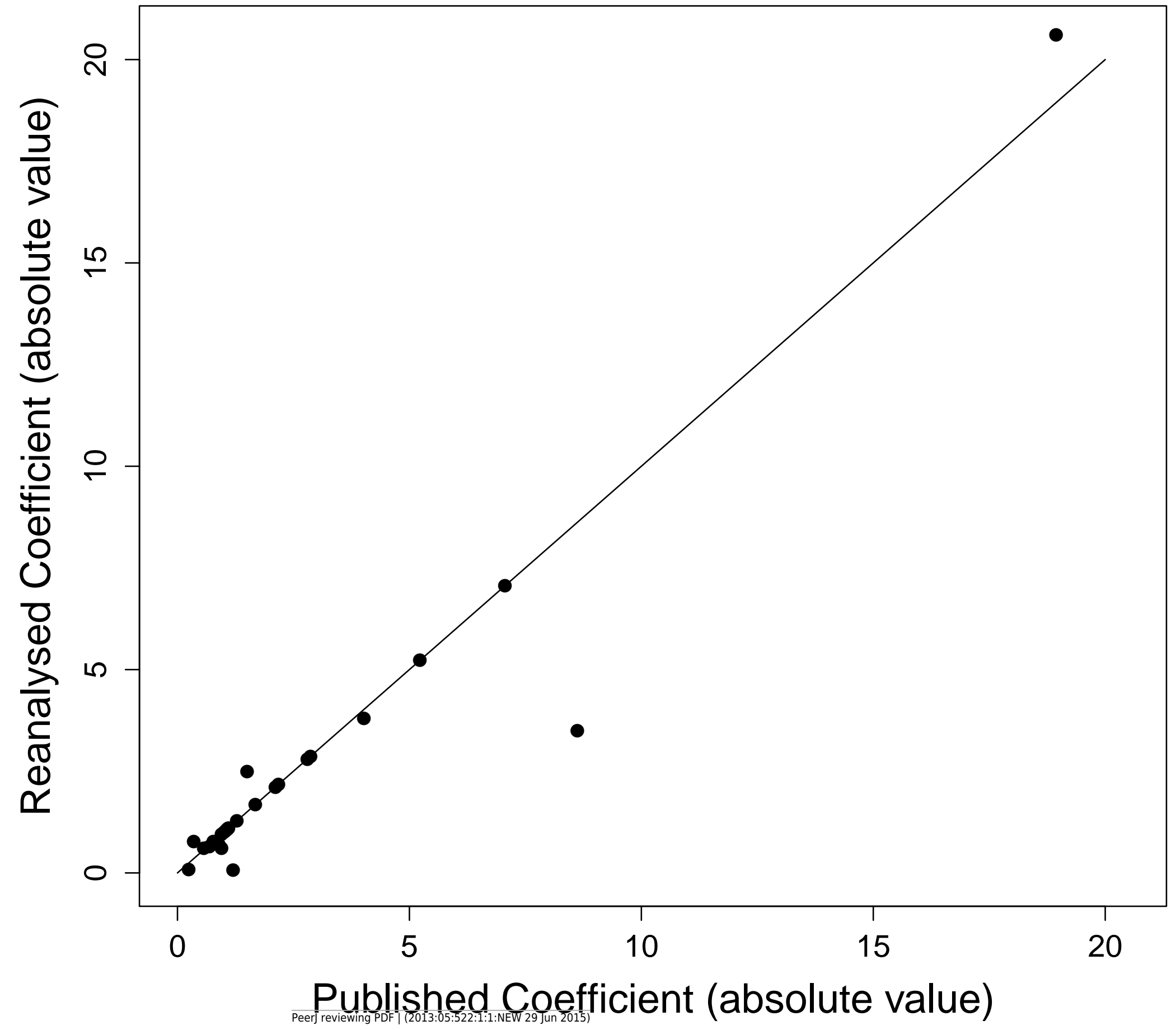

